\title{
Multigenic factors associated with a hydrocephalus-like phenotype found in inter-subspecific consomic mouse strains
}

\author{
Aki Takahashi · Toshihiko Shiroishi · \\ Tsuyoshi Koide
}

Published online: 2 July 2008

(C) Springer Science+Business Media, LLC 2008

\section{Erratum to: Mamm Genome}

\section{DOI 10.1007/s00335-008-9112-2}

In the above-mentioned article, published in SpringerLink on May 29 2008, the affiliations of authors A. Takahashi and T. Shiroishi were inadvertently switched. Per PubMed and SpringerLink regulations, the online and print versions of all articles must exactly duplicate each other. Therefore the incorrect affiliations are shown in the print article, which appears in this issue following this Erratum.

We would like to extend our sincere apology to the authors for this error.

The correct list of affiliations for all authors is shown below. The postcode of the National Institute of Genetics has also been corrected.

The online version of the original article can be found under doi:10.1007/s00335-008-9112-2.

A. Takahashi $\cdot$ T. Koide $(\bowtie)$

Mouse Genomics Resource Laboratory, National Institute of Genetics, 1111 Yata, Mishima, Shizuoka 411-8540, Japan

e-mail: tkoide@lab.nig.ac.jp

A. Takahashi - T. Shiroishi - T. Koide

Department of Genetics, The Graduate University for Advanced

Studies (SOKENDAI), Hayama, Kanagawa 240-0193, Japan

Present Address:

A. Takahashi

Psychology Department, Tufts University,

530 Boston Avenue (Bacon Hall), Medford, MA 02155, USA

T. Shiroishi

Mammalian Genetics Laboratory, National Institute of Genetics,

1111 Yata, Mishima, Shizuoka 411-8540, Japan 